\title{
A Hybrid Method of GRA and DEA for Evaluating and Selecting Efficient Suppliers plus a Novel Ranking Method for Grey Numbers
}

\author{
Mohsen Sayyah Markabi, Mohammad Sabbagh \\ Isfahan University of Technology (Islamic Republic of Iran) \\ m.sayyahmarkabi@in.iut.ac.ir,sabbagh@,cc.iut.ac.ir
}

Received: May 2013

Accepted: July 2014

\section{Abstract:}

Purpose: Evaluation and selection of efficient suppliers is one of the key issues in supply chain management which depends on wide range of qualitative and quantitative criteria. The aim of this research is to develop a mathematical model for evaluating and selecting efficient suppliers when faced with supply and demand uncertainties.

Design/methodology/approach: In this research Grey Relational Analysis (GRA) and Data Envelopment Analysis (DEA) are used to evaluate and select efficient suppliers under uncertainties. Furthermore, a novel ranking method is introduced for the units that their efficiencies are obtained in the form of interval grey numbers.

Findings: The study indicates that the proposed model in addition to providing satisfactory and acceptable results avoids time-consuming computations and consequently reduces the solution time. To name another advantage of the proposed model, we can point out that it enables us to make decision based on different levels of risk.

Originality/value: The paper presents a mathematical model for evaluating and selecting efficient suppliers in a stochastic environment so that companies can use in order to make better decisions.

Keywords: efficient suppliers, Grey Relational Analysis, Data Envelopment Analysis, ranking method, grey numbers 


\section{Introduction}

Nowadays, globalization and fierce competition in the markets and the business environments have made it more difficult for organizations to survive. This issue has caused the creation of supply chain management philosophy. Indeed, supply chain management is the integration of organizational units across the supply chain and harmonization of the flow of materials, information, and capital. The problem of evaluating the efficiency of supply chain involves wide range of efficiency evaluation of independent organizations across the supply chain. Such a job is regarded as a vital strategic decision making problem that requires considering long-range operations in the entire supply chain.

Commonly in the supply chain, organizations such as marketing, distributing, planning, production, and purchasing are independent units. As the importance of the purchasing function grows, the sensitivity of decisions related to it will be increased accordingly. Hence, decisions about strategies and purchasing operations play a dominant role in the profitability. Supplier selection is one of the important schemes in the area of purchase management. Therefore, in response to rising competitiveness, shortening product life cycle, and quick changes in customer's needs and tastes, most companies have focused on developing long-term capabilities of their suppliers. This concern reveals the importance of evaluation and selection of suppliers.

Generally speaking, the objective of evaluating and selecting models is to propose a quantitative model so as to direct managers towards lean production and reduction in number of suppliers. In the last few decades, the issue of supplier selection has been widely studied in the supply chain literature. The issue of supplier selection is formed by integrating the following two decisions: 1) which supplier(s) should be selected? , and 2) what portion of purchase should be ordered to each selected supplier? (Ghodsypour \& O'Brien, 1998). By integrating two problems of order lot-sizing with supplier selection, Basnet and Leung (2005) introduced a new problem entitled "determining the size of multi-term order along with supplier selection" in which they only considered the qualitative factors and solved it by applying an enumerative heuristic algorithm. In their research, demand for merchandises was given in the planning horizon and any merchandise could be purchased from the set of selected suppliers. Their proposed model helps the decision makers to answer these questions: which merchandises and how much should be purchased in which term and from which supplier? Narasimhan, Talluri and Mendez (2001) have applied the DEA model for evaluating the alternative suppliers in multi-national communication companies. In the model, eleven evaluation criteria have been considered, where five of which referred to the ability of suppliers and six criterial related with the efficiency of the suppliers. According to the efficiency score obtained, suppliers are divided into four categories: high and effective efficiency, high and ineffective efficiency, low and effective efficiency, and finally low and ineffective efficiency. Talluri and Baker (2002) have used a three-staged procedure for designing logistic distribution 
network. In the first stage, potential stakeholders that consist of suppliers, producers, and distributors are separately evaluated by means of DEA method. Six criteria for evaluating suppliers have been suggested where two of them are input and the remaining are output. Based on the obtained efficiency scores in the first stage and optimal number of stakeholders from the second stage, the optimal path from selected suppliers to producers and from producers to storage are identified. Garfamy (2006) has applied DEA for evaluating the efficiency of suppliers by considering the attributes and functional criteria of suppliers and buyers. Three sensitivity analyses were carried out. The first analysis was to compute the supplier efficiency scores without considering the evaluation team's weights and restrictions. The second analysis considered the evaluation team's preferences on the supplier performance attributes, where the third analysis considered the buyer's preferences on the supplier performance attributes. Talluri, Narasimhan and Nair (2006) presented a DEA model with random constraints accompanied by random efficiency tools for evaluating the efficiency of the suppliers. In the model, price has been considered as input parameter while quality and delivery as output parameters. Moreover, in order to show the capability of the model, it is compared with exact DEA model. Wu, Shunk, Blackhurst and Appalla (2007) introduced a non-exact DEA method for supplier selection such that their model can be used by non-exact data (for ranking efficient suppliers); in addition, it raises prejudice (prejudice between efficient and non-efficient suppliers). Also, they developed a system for selecting potential buyers based on the web. Talluri and Narasimhan (2005) proposed a linear programming model for evaluating and selecting potential suppliers with respect to the strength points of suppliers and omitting weak performance of suppliers. In order to demonstrate the relative advantages the model, the proposed model was compared with ordinary and advanced DEA model. A hybrid DEA model and fuzzy grey relative analysis have been proposed by Wu and Olson (2010) for the problem of ranking. In the proposed model, numbers are considered to be grey. Also, the coefficients of the grey relation are computed and then applied in the model in order to do the ranking. Saen (2007) has introduced a hybrid Analytic Hierarchy Process (AHP)-DEA method for evaluating and selecting suppliers. The AHP is used for finding relative weights of suppliers whose input or output data are not available and on the other hand DEA is utilized to compute relative efficiency of any supplier.

Hong, Park, Jang and Rho (2005) have proposed a Mixed-Integer Linear Programming model for the problem of supplier selection such that it determines the optimal number of suppliers, optimizes the amount of order, and maximizes income. Moreover, they consider the changes in suppliers' supply capabilities and customer needs in a single time interval. In another attempt, Narasimhan, Talluri and Mahapatra (2006) have presented a Multi-Objective Programming model for selecting optimal supplier and indicating the optimal amount of order. Five criteria for evaluating the performance of suppliers have been considered. The weights of theses five criteria are computed by applying the AHP before solving the model. A five-staged AHP model has been proposed by Muralidharan, Anantharaman and Deshmukh (2002) for selecting and 
ranking suppliers according to nine evaluating criteria. Analogously, Hou and Su (2007) have proposed an AHP model for selecting suppliers in a condition where there are plenty of orders. Criteria are assumed to be under influence of internal and external factors for satisfying needs of the market. Gencer and Gürpinar (2007) have considered an Analytic Network Process (ANP) model for evaluating and selecting a proper supplier according to several evaluating criteria in which criteria fall in three categories. In the selection process, the mutual relation between criteria has been taken into account. Sarkar and Mohapatra (2006) using the fuzzy set approach, have tried to explain the process of supplier selection based on performance and capability. To show how this procedure works, they selected the two best suppliers with respect to four performance-based and ten capability-based factors. Kahraman, Cebeci and Ulukan (2003) have applied a fuzzy AHP for picking the best supplier. In their model, decision makers indicate the importance of each evaluating criterion using linguistic variables. Mendoza, Santiago and Ravindran (2008) have proposed a hybrid AHP-Goal Programming (GP) method for reducing the high number of suppliers, ranking them according to five criteria and determining the optimal order quantity. Chen and Huang (2007) have combined the AHP method with Multi-Attribute Negotiation Mechanism for supplier selection. The proposed model enables the buyers and suppliers to negotiate over multi-attributes for a transaction, including assets, business criteria, cost, and delivery. Choy and Lee (2002) have developed a general model using a Case-Based Reasoning (CBR) technique for supplier selection. Categorization criteria are classified as technical capability, quality system and structural attributes.

Demirtas and Üstün (2008) have developed a hybrid ANP model along with multi-objective mixed integer linear programming for selecting the best supplier and also finding optimal order allocation. Evaluating the performance of the potential suppliers is done by applying 14 criteria and the priorities are incorporated into one of the three objective functions. Lau, Lee, Ho and Pun (2006) developed a hybrid Artificial Neural Network (ANN)-Genetic Algorithm (GA) model in order to select suppliers. In their model, in the first stage, ANN is used for evaluating potential suppliers considering four criteria and in the next stage GA is applied for selecting a combination of best suppliers.

In this research a mathematical model for evaluating and selecting efficient suppliers by applying a grey relational analysis and data envelopment analysis under uncertainty is proposed. Furthermore, a novel ranking method for those units whose efficiencies are computed as grey numbers is presented. The rest of this paper is organized as follow: in section 2, principles of grey numbers, grey relational analysis, and ranking methods of average and Minimax Regret Approach (MRA) will be discussed. In section 3, a proposed method for ranking efficient suppliers using a combined grey relational analysis and data envelopment analysis is presented; moreover, a new ranking method for grey numbers is introduced. Some numerical examples for the proposed model and the ranking method are presented in section 4 and finally section 5 contains conclusion and directions for future studies. 


\section{Preliminaries}

\subsection{Grey number theory}

Grey number theory is one of the latest theories that has been developed based on the concept of grey set by Deng (1982). This theory has found many interesting applications in various branches (Lin, Chang \& Chen, 2006). According to the grey number theory, the system with clear information is called white. On the other hand, if no information is available that system is called black. A system with partially known information is recognized as the grey system.

\subsubsection{Principal definitions of grey number theory}

Definition 1. A grey number with lower bound and without upper bound is defined as follows:

$$
\otimes G=[\underline{G}, \infty)
$$

Definition 2. A grey number with upper bound and without lower bound is defined as follows:

$$
\otimes G=(-\infty, \bar{G}]
$$

Definition 3. A grey number that has lower and upper bounds is named "interval grey number" and is defined as follows:

$$
\otimes G=[\underline{G}, \bar{G}]
$$

Definition 4. Grey number $\otimes G=[\underline{G}, \bar{G}]$ can be shown as

$$
[\underline{G}, \bar{G}]=\underline{G}+(\bar{G}-\underline{G}) * \alpha, 0 \leq \alpha \leq 1
$$

Definition 5. Let $\otimes G_{1}=\left[\underline{G}_{1}, \overline{G_{1}}\right]$ and $\otimes G_{2}=\left[\underline{G}_{2}, \overline{G_{2}}\right]$ be two grey numbers, four main operations for these two numbers are

$$
\begin{gathered}
\otimes G_{1}+\otimes G_{2}=\left[\underline{G}_{1}+\underline{G}_{2}, \overline{G_{1}}+\overline{G_{2}}\right] \\
\otimes G_{1}-\otimes G_{2}=\left[\underline{G}_{1}-\overline{G_{2}}, \overline{G_{1}}-\underline{G}_{2}\right] \\
\otimes G_{1} \times \otimes G_{2}=\left[\min \left(\underline{G}_{1} \underline{G}_{2}, \underline{G}_{1} \overline{G_{2}}, \overline{G_{1}} \underline{G}_{2}, \overline{G_{1}} \overline{G_{2}}\right), \max \left(\underline{G}_{1} \underline{G}_{2}, \underline{G}_{1} \overline{G_{2}}, \overline{G_{1}} \underline{G}_{2}, \overline{G_{1}} \overline{G_{2}}\right)\right] \\
\otimes G_{1} \div \otimes G_{2}=\left[\underline{G}_{1}, \overline{G_{1}}\right] \times\left[\frac{1}{\overline{G_{2}}}, \frac{1}{\underline{G}_{2}}\right]
\end{gathered}
$$

Definition 6 . The length of the grey number $\otimes G$ is

$$
L(\otimes G)=[\bar{G}-\underline{G}]
$$




\subsubsection{Grey Relational Analysis (GRA)}

Grey relational analysis is part of grey number theory which is suitable for solving problems with complicated relations among variables and multiple factors (Morán, Granada, Míguez \& Porteiro, 2006). The GRA has been successfully applied in some multiple attribute decision making (MADM) problems such as employment issue (Olson \& Wu, 2006), planning for repairing the electricity distribution systems (Chen, 2005), and modeling the establishment of quality function $(\mathrm{Wu}, 2002)$.

The main procedure of GRA is first of all translating the performance of all alternatives into a comparable sequence; this step is referred as production of grey relation. A reference sequence is defined with respect to these sequences. Then, the coefficients of grey relation between the comparable sequence and the reference sequence are computed. Based on computed coefficients of grey relation, the degree of grey relation between reference sequence and comparable sequences is calculated. Finally, the alternative associated with the sequence that has earned the highest degree and score is selected as a superior alternative. The steps of GRA procedure is as follows:

\subsubsection{Grey Relation Generation}

Let there be $m$ alternatives and $n$ criteria in a MADM problem. The $i$ th alternative can be shown as $Y_{i}=\left(y_{i 1}, y_{i 2}, \ldots, y_{i j}, \ldots, y_{i n}\right)$, where $y_{i j}$ is the functionality of alternative $i$ th in $j$ th criterion. By using the following relations, $Y_{i}$ can be converted to the comparable sequence $X_{i}=\left(x_{i 1}, x_{i 2}, \ldots, x_{i j}\right.$, $\left.\ldots, x_{i n}\right)$.

$$
\begin{gathered}
x_{i j}=\frac{y_{i j}-\operatorname{Min}\left\{y_{i j}, i=1,2, \ldots, m\right\}}{\operatorname{Max}\left\{y_{i j}, i=1,2, \ldots, m\right\}-\operatorname{Min}\left\{y_{i j}, i=1,2, \ldots, m\right\}} \\
i=1,2, \ldots, m, j=1,2, . ., n \\
x_{i j}=\frac{\operatorname{Max}\left\{y_{i j}, i=1,2, \ldots, m\right\}-y_{i j}}{\operatorname{Max}\left\{y_{i j}, i=1,2, \ldots, m\right\}-\operatorname{Min}\left\{y_{i j}, i=1,2, \ldots, m\right\}} \\
i=1,2, \ldots, m, j=1,2, . ., n \\
x_{i j}=1-\frac{\left|y_{i j}-y_{j}{ }^{*}\right|}{\operatorname{Max}\left\{\operatorname{Max}\left\{y_{i j}, i=1,2, \ldots, m\right\}-y_{j}{ }^{*}, y_{j}{ }^{*}-\operatorname{Min}\left\{y_{i j}, i=1,2, \ldots, m\right\}\right\}} \\
i=1,2, \ldots, m, j=1,2, . ., n
\end{gathered}
$$

Where, relations (10) and (11) are applied for positive and negative criteria respectively and relation (12) is for the time when values are close to ideal value. 


\subsubsection{Reference sequence}

After obtaining grey relation by relation (10), (11), or (12) all the functionality values will fall in interval $[0,1]$. Higher value of $x_{i j}$ in comparison with other alternatives or its closeness to 1 shows the better functionality of alternative $i$ th in criterion $j$ th. Since such an alternative usually does not exist, the reference sequence is defined as $\left(x_{01}, x_{02}, \ldots, x_{0 j}, \ldots, x_{0 n}\right)=(1,1, \ldots, 1, \ldots, 1)$.

\subsubsection{Computing the relational grey coefficient}

The relational grey coefficient is for determining the closeness of $x_{i j}$ to $x_{0 j}$. The greater $x_{i j}$, the closer $x_{i j}$ to $x_{0 j}$. The relational grey coefficient is given by

$$
\begin{aligned}
& \gamma\left(x_{0 j}, x_{i j}\right)=\frac{\Delta_{\min }+\zeta \Delta_{\max }}{\Delta_{i j}+\zeta \Delta_{\max }} \\
& i=1,2, \ldots, m, \quad j=1,2, . ., n
\end{aligned}
$$

Where, $\gamma\left(x_{0 j}, x_{i j}\right)$ is relational grey coefficient between $x_{i j}$ and $x_{0 j}$. Other terms are

$$
\begin{gathered}
\Delta_{i j}=\left|x_{0_{j}}-x_{i j}\right| \\
\Delta_{\text {min }}=\operatorname{Min}\left\{\Delta_{i j}, i=1,2, \ldots, m ; j=1,2, \ldots n\right\} \\
\Delta_{\max }=\operatorname{Max}\left\{\Delta_{i j}, i=1,2, \ldots, m ; j=1,2, \ldots n\right\}
\end{gathered}
$$

In which, $\zeta \in[0,1]$ is the recognition coefficient.

\subsubsection{Computation of relational grey degree}

After computing the relational grey coefficient $\gamma\left(x_{0 j}, x_{i j}\right)$, the relational grey degree is calculated through relation (17).

$$
\Gamma\left(X_{0}, X_{i}\right)=\sum_{j=1}^{n} w_{j} \gamma\left(x_{0 j}, x_{i j}\right) \quad i=1,2, \ldots, m
$$

In relation (17), $\Gamma\left(X_{0}, X_{i}\right)$ is the relational grey degree between $x_{0}$ and $x_{i}$ that shows the correlation between the reference and current sequence and $w_{j}$ is the weight of the $j$ th criterion and $\sum_{j=1}^{n} w_{j}=1$. Relational grey degree demonstrates the similarity between the reference and current competitive sequence. The alternative that earns the highest degree is selected as the best alternative. 


\subsubsection{Data Envelopment Analysis}

Developed by Charnes, Cooper and Rhodes (1978), data envelopment analysis is a technique for evaluating the efficiency of decision making units (DMUs). In other words, data envelopment analysis is applied for evaluating the efficiency of homogeneous organizational units with multiple inputs and outputs which are called decision making units (Cooper, Seiford \& Tone, 2000). CCR and BCC are two models for evaluating the efficiency of decision making units.

\subsubsection{CCR model}

CCR is one of the models for evaluating the decision making units. The relative efficiency of $\mathrm{DMU}_{0}$ is calculated via relation (18):

$$
e_{0}=\frac{\sum_{r=1}^{s} u_{r} y_{r 0}}{\sum_{i=1}^{m} v_{i} x_{i 0}}
$$

The objective is to maximize the amount of relation (18). Hence, we arrive at:

$$
\begin{array}{r}
\operatorname{Max} e_{0}=\frac{\sum_{r=1}^{s} u_{r} y_{r 0}}{\sum_{i=1}^{m} v_{i} x_{i 0}} \\
\text { s.t. }\left\{\begin{array}{l}
\sum_{r=1}^{s} u_{r} y_{r j} \\
\sum_{i=1}^{m} v_{i} x_{i j} \\
v_{i}, u_{r} \geq 0
\end{array}\right.
\end{array}
$$

Where $j=1,2, \ldots, n, i=1,2, \ldots, m$ and $r=1,2, \ldots, s$. Also, some boundary conditions must be set for the problem. In order to convert the problem (19) to a linear problem, relation (20) is introduced:

$$
\sum_{i=1}^{m} v_{i} x_{i 0}=\frac{1}{t}, t \geq 0
$$


Accordingly, the problem reduces to:

$$
\begin{array}{ll}
\operatorname{Max} & \sum_{r=1}^{s} u_{r} y_{r 0} \\
\text { s.t. } & \left\{\begin{array}{l}
\sum_{i=1}^{m} v_{i} x_{i 0}=1 \\
\sum_{i=1}^{m} v_{i} x_{i j}-\sum_{r=1}^{s} u_{r} y_{i j} \geq 0 \\
v_{i}, u_{r} \geq 0
\end{array}\right.
\end{array}
$$

Where $j=1,2, \ldots, n, i=1,2, \ldots, m$ and $r=1,2, \ldots, s$. This problem is known as input-oriented CCR method. Dual of the model (21) is as follows:

$$
\begin{aligned}
& \operatorname{Min} \theta \\
& \text { s.t. }\left\{\begin{array}{l}
\sum_{j=1}^{n} \lambda_{j} x_{i j} \leq \theta x_{i 0} \\
\sum_{j=1}^{n} \lambda_{j} y_{i j} \geq y_{r 0} \\
\lambda_{j} \geq 0
\end{array}\right.
\end{aligned}
$$

Where $j=1,2, \ldots, n, i=1,2, \ldots, m$ and $r=1,2, \ldots, s$. The output-oriented model is given at relation (23):

$$
\begin{array}{ll}
\operatorname{Max} & \varphi \\
\text { s.t. } & \left\{\begin{array}{l}
\sum_{j=1}^{n} \lambda_{j} x_{i j} \leq x_{i 0} \\
\sum_{j=1}^{n} \lambda_{j} y_{r j} \geq \varphi y_{r 0} \\
\lambda_{j} \geq 0
\end{array}\right.
\end{array}
$$

In which, $j=1,2, \ldots, n, i=1,2, \ldots, m$ and $r=1,2, \ldots, s$. Now, consider problem (22). By defining slack variables, the problem turns into the following form (relation (24)): 


$$
\begin{aligned}
& \operatorname{Min} \theta \\
& \text { s.t. }\left\{\begin{array}{l}
\sum_{j=1}^{n} \lambda_{j} x_{i j}-s_{i}^{-}=\theta x_{i 0} \\
\sum_{j=1}^{n} \lambda_{j} y_{r j}+s_{r}^{+}=y_{r 0} \\
\lambda_{j} \geq 0 \\
s_{r}^{+}, s_{i}^{-} \geq 0
\end{array}\right.
\end{aligned}
$$

Where $j=1,2, \ldots, n, i=1,2, \ldots, m$ and $r=1,2, \ldots, s$.

\subsubsection{BCC model}

The input-oriented model seeks a convex combination of DMUs such that it generates the same output with minimum possible input. Considering the Variable Return to Scale (RTS) condition, the problem is changed to (25):

$$
\begin{aligned}
& \operatorname{Min} \theta \\
& \text { s.t. }\left\{\begin{array}{l}
\sum_{j=1}^{n} \lambda_{j} x_{i j} \leq \theta x_{i 0} \\
\sum_{j=1}^{n} \lambda_{j} y_{r j} \geq y_{r 0} \\
\sum_{j=1}^{n} \lambda_{j}=1 \\
\lambda_{j} \geq 0
\end{array}\right.
\end{aligned}
$$

Where $j=1,2, \ldots, n, i=1,2, \ldots, m$ and $r=1,2, \ldots, s$. The above model is defined as input-oriented BCC model. Indeed, the output looks for a convex combination of DMUs such that with the same inputs, maximum output is generated. Thus, by considering Variable Return to Scale condition, the problem is updated to (26):

$$
\begin{aligned}
& \operatorname{Max} \varphi \\
& \text { s.t. }\left\{\begin{array}{l}
\sum_{j=1}^{n} \lambda_{j} x_{i j} \leq x_{i 0} \\
\sum_{j=1}^{n} \lambda_{j} y_{i j} \geq \varphi y_{r 0} \\
\sum_{j=1}^{n} \lambda_{j}=1 \\
\lambda_{j} \geq 0
\end{array}\right.
\end{aligned}
$$

Where $j=1,2, \ldots, n, i=1,2, \ldots, m$ and $r=1,2, \ldots, s$. 


\subsubsection{Envelopment analysis of grey data interval}

Let there be $n$ decision making units such that each of them has $m$ input and $s$ output. Now, the relative efficiency of $\mathrm{DMU}_{0}$ is obtained through solving the following model:

$$
\begin{aligned}
& \operatorname{Max} \quad \theta_{0}=\sum_{r=1}^{s} u_{r}\left[\underline{y_{r 0}}, \overline{y_{r 0}}\right] \\
& \text { s.t. }\left\{\begin{array}{l}
\sum_{i=1}^{m} v_{i}\left[\underline{x_{i j}}, \overline{x_{i j}}\right]-\sum_{r=1}^{s} u_{r}\left[\underline{y_{r j}}, \overline{y_{r j}}\right] \geq 0 \\
j=1, \ldots, n, j \neq 0 \\
\sum_{i=1}^{m} v_{i}\left[\underline{x_{i 0}}, \overline{x_{i 0}}\right]=1 \\
v_{i}, u_{r} \geq 0, \forall i, r
\end{array}\right.
\end{aligned}
$$

Where $r=1,2, \ldots, s, i=1,2, \ldots, m$ and $j=1,2, \ldots, n$. Also, $x_{i j}=\left[\underline{x_{i j}}, \overline{x_{i j}}\right]$ and $y_{i j}=\left[\underline{y_{i j}}, \overline{y_{i j}}\right]$ are the inputs and outputs, respectively $y_{r j}$ is the output generated by $\mathrm{DMU}_{\mathrm{j}}, x_{i j}$ is the input used by $\mathrm{DMU}_{\mathrm{j}}, u_{r}$ is the weight of the $r$ th output and finally $v_{i}$ is the weight of the $i$ th input.

The maximum efficiency of $\mathrm{DMU}_{0}$ occurs once it generates the maximum output by use of minimum input, whereas, other DMUs generate the least output by using maximum amount of input. The mathematical model for the maximum efficiency of $\mathrm{DMU}_{0}$ is as below:

$$
\begin{aligned}
& \operatorname{Max} \overline{\theta_{0}}=\sum_{r=1}^{s} u_{r} \overline{y_{r 0}} \\
& \text { s.t. }\left\{\begin{array}{l}
\sum_{i=1}^{m} v_{i} \overline{x_{i j}}-\sum_{r=1}^{s} u_{r} \underline{y_{r j}} \geq 0 \\
j=1, \ldots, n, j \neq 0 \\
\sum_{i=1}^{m} v_{i} \underline{x_{i 0}}=1 \\
v_{i}, u_{r} \geq 0, \forall i, r
\end{array}\right.
\end{aligned}
$$

Additionally, the minimum efficiency for the $\mathrm{DMU}_{0}$ takes place when it generates the least output by using the maximum input, whereas, other DMUs generate the maximum output by using the minimum input. The mathematical model for the minimum efficiency of $\mathrm{DMU}_{0}$ is:

$$
\begin{aligned}
& \operatorname{Max} \quad \underline{\theta_{0}}=\sum_{r=1}^{s} u_{r} \underline{y_{r 0}} \\
& \text { s.t. }\left\{\begin{array}{l}
\sum_{i=1}^{m} v_{i} \underline{x_{i j}}-\sum_{r=1}^{s} u_{r} \overline{y_{i j}} \geq 0 \\
j=1, \ldots, n, j \neq 0 \\
\sum_{i=1}^{m} v_{i} \overline{x_{i 0}}=1 \\
v_{i}, u_{r} \geq 0, \forall i, r
\end{array}\right.
\end{aligned}
$$


Hence, the efficiency of $\mathrm{DMU}_{0}$ is shown as $\theta_{0}=\left[\underline{\theta_{0}}, \overline{\theta_{0}}\right]$.

According to the above mentioned models, the efficiency of DMUs is consist of three categories:

1. $E^{*}=\left\{D M U_{j} \mid \underline{\theta_{j}} \geq 1, j=1, \ldots, n\right\}$, in this case the DMU is efficient.

2. $E=\left\{D M U_{j} \mid \underline{\theta_{j}} \leq 1, \overline{\theta_{j}} \geq 1, j=1, \ldots, n\right\}$, in this case the DMU is almost efficient.

3. $F=\left\{D M U_{j} \mid \overline{\theta_{j}} \leq 1, j=1, \ldots, n\right\}$, in this case the DMU is not efficient.

\subsubsection{Ranking method of DMUs based on interval efficiency}

\subsubsection{The average method}

One of the methods used for ranking DMUs is the average method which is defined as

$$
\left[\theta_{j}, \overline{\theta_{j}}\right] \leq\left[\underline{\theta_{k}}, \overline{\theta_{k}}\right] \Leftrightarrow \frac{\theta_{j}+\overline{\theta_{j}}}{2} \leq \frac{\theta_{k}+\overline{\theta_{k}}}{2}
$$

\subsubsection{Minimax Regret Approach (MRA)}

Let $A_{j}=\left[\underline{\theta_{j}}, \overline{\theta_{j}}\right]=<m\left(A_{j}\right), w\left(A_{j}\right)>$ to be the efficiency of $j$ th DMU such that $m\left(A_{j}\right)=\frac{1}{2}\left(\overline{\theta_{j}}+\underline{\theta_{j}}\right)$ and $w\left(A_{j}\right)=\frac{1}{2}\left(\overline{\theta_{j}}-\underline{\theta_{j}}\right)$ are the middle points and width of intervals, respectively. Without losing generality, it is assumed that $A_{j}=\left[\underline{\theta_{j}}, \overline{\theta_{j}}\right]$ is the best efficiency of the interval. Let $b=\max _{j \neq i}\left\{\bar{\theta}_{j}\right\}$, it is obvious that if $\underline{\theta_{j}}<b$ then the decision maker feels regret due to losing efficiency. The maximum efficiency that the decision maker can lose is $\max \left(r_{j}\right)=b-\underline{\theta_{j}}=\max _{i \neq j}\left\{\bar{\theta}_{i}\right\}-\underline{\theta_{j}}$. If $\underline{\theta_{j}} \geq b$ then the decision maker will not feel regret since he (she) has not lost efficiency. In this case, the amount of regret is zero, i.e. $r_{j}=0$. Combining the above two cases, we have

$$
\max \left(r_{j}\right)=\max \left[\max _{i \neq j}\left\{\overline{\theta_{i}}\right\}-\underline{\theta_{j}}, 0\right]
$$

Therefore, the minimax regret criterion selects the best interval efficiency as the satisfactory efficiency. 


$$
\min _{j}\left\{\max \left(r_{j}\right)\right\}=\min _{j}\left\{\max \left[\max _{i \neq j}\left\{\bar{\theta}_{i}\right\}-\underline{\theta_{j}}, 0\right]\right\}
$$

Based on the above analysis, we have the following definition for comparing and ranking interval efficiency:

Definition 7. Let $A_{j}=\left[\theta_{j}, \overline{\theta_{j}}\right]=<m\left(A_{j}\right), w\left(A_{j}\right)>, j=1,2, \ldots, n$ be an interval efficiency set. The maximum amount of lost efficiency (maximum regret) for each $A_{j}$ is

$$
R\left(A_{j}\right)=\max \left[\max _{i \neq j}\left\{\bar{\theta}_{i}\right\}-\underline{\theta_{j}}, 0\right]=\max \left[\max _{i \neq j}\left\{m\left(A_{i}\right)+w\left(A_{i}\right)\right\}-\left(m\left(A_{j}\right)-w\left(A_{j}\right)\right), 0\right], j=1,2, \ldots, n
$$

As it was mentioned, best condition is when the minimum efficiency has been lost. To rank interval efficiency by use of the maximum lost efficiency, the following steps are suggested:

Step 1. Calculate the maximum lost efficiency for each interval and select the one with the minimum lost efficiency (minimum regret) as a suitable efficiency interval. Assume that $A_{j 1}, 1 \leq j_{1} \leq n$ is selected as the suitable efficiency interval.

Step 2. Omit $A_{j 1}$ from the set and calculate the maximum lost efficiency for the $(n-1)$ remaining efficiency once again. Assume that in this step, $A_{j 2}, 1 \leq j_{2} \leq n, j_{2} \neq j_{1}$ is selected.

Step 3. Omit $A_{j 2}$ from the set and calculate the maximum lost efficiency for the $(n-2)$ remaining efficiency one more time and then assume $A_{j 3}$ is selected in this step.

Step 4. Continue the above process until only one interval efficiency $\left(A_{j n}\right)$ is left. The final ranking will be $A_{j 1}>A_{j 2}>\ldots>A_{j n}$ in which notation $>$ means superiority.

\section{The proposed method}

\subsection{The proposed method for ranking grey numbers}

Definition 8 . Let $\otimes x=[\underline{x}, \bar{x}]$ and $\otimes y=[\underline{y}, \bar{y}]$ be two grey numbers, therefore, the Euclidean distance between two numbers $\otimes x$ and $\otimes y$ is

$$
L_{2}(\otimes x, \otimes y)=2^{-\frac{1}{2}}\left[\bar{x}-\left.\bar{y}\right|^{2}+|\underline{x}-\underline{y}|^{2}\right]^{\frac{1}{2}}
$$

Definition 9. Let $\otimes x=\left[\otimes x_{1}, \otimes x_{2}, \ldots \otimes x_{m}\right]$ and $\otimes \psi=\left[\otimes y_{1}, \otimes y_{2}, \ldots \otimes y_{m}\right]$ be two $m$-dimensional grey number. Thus, the Minkowski metric between $\otimes x$ and $\otimes y$ is

$$
L_{2}(\otimes x, \otimes y)=2^{-\frac{1}{p}}\left[\left|\bar{x}_{1}-\bar{y}_{1}\right|^{p}+\left|\underline{x}_{1}-\underline{y}_{1}\right|^{p}+\ldots+\left|\bar{x}_{m}-\bar{y}_{m}\right|^{p}+\left|\underline{x}_{m}-\underline{y}_{m}\right|^{p}\right]^{\frac{1}{p}}
$$


Assume that $A_{j}=\left[\theta_{j}, \overline{\theta_{j}}\right]$ is the efficiency of $\mathrm{DMU}_{j}$. The proposed steps for ranking interval efficiency are as follows

Step 1 . Indicating $I^{\max }$ and $I^{\min }$ by utilizing the following relations:

$$
\begin{aligned}
I^{\max } & =\left[\max \underline{\theta_{j}}, \max \overline{\theta_{j}}\right] \\
I^{\min } & =\left[\min \underline{\theta_{j}}, \min \overline{\theta_{j}}\right]
\end{aligned}
$$

Where $I^{\max }$ and $I^{\mathrm{min}}$ are recognized as criterion for computing interval distances.

Step 2. using the following equations the distance of each interval from $I^{\max }$ and $I^{\min }$ is calculated:

$$
\begin{aligned}
L_{2}^{\max }\left(A_{j}, I^{\max }\right) & =2^{-\frac{1}{2}}\left[\left|\max \overline{\theta_{j}}-\overline{\theta_{j}}\right|^{2}+\left|\max \underline{\theta_{j}}-\underline{\theta_{j}}\right|^{2}\right]^{\frac{1}{2}} \\
L_{2}{ }^{\min }\left(A_{j}, I^{\min }\right) & =2^{-\frac{1}{2}}\left[\overline{\theta_{j}}-\left.\min \overline{\theta_{j}}\right|^{2}+\left|\underline{\theta_{j}}-\min \underline{\theta_{j}}\right|^{2}\right]^{\frac{1}{2}}
\end{aligned}
$$

Step 3. Calculate the ratio of $\varepsilon_{j}$ by using the following relation:

$$
\varepsilon_{j}=\frac{L_{2}^{\min }}{L_{2}^{\min }+L_{2}^{\max }}
$$

The closer the value of this ratio to 1 the higher is the ranking.

\subsection{The proposed model for evaluating and selecting efficient suppliers}

Since the original values for the inputs and outputs are grey (interval), first using $[a, b]=a+\alpha^{*}(b-a), 0 \leq \alpha \leq 1$ for different risk levels $\alpha=0,0.25,0.5,0.75,1$ the original grey values are converted to exact ones and afterward for each value of $\alpha$ the efficiency of supplier is obtained through DEA. At the end, a matrix will be generated that rows and columns respectively indicate the number of suppliers and their computed efficiency for different values of $\alpha$. After that, the steps of GRA are applied and consequently the final ranking of supplier will be accomplished.

The above descriptions can be stated in the form of following algorithm:

Step 1. Convert the grey numbers (interval) to exact numbers in different levels of risk $\alpha$ via this relation $[a, b]=a+\alpha^{*}(b-a), 0 \leq \alpha \leq 1$. 
Step 2. Calculate the efficiency of suppliers for different values of $\alpha$ using DEA.

Step 3. Generate the initial GRA matrix where its rows are the suppliers numbers and its columns the computed efficiency via DEA for different values of $\alpha$.

Step 4. Apply the GRA approach for final ranking of suppliers.

To measure the efficiency, GAMS 23.4 software has been applied.

\section{Computational results}

We consider the problem that introduced in (Farzipoor Saen, 2010). By using the relation $[a, b]=a+\alpha^{*}(b-a), 0 \leq \alpha \leq 1$ for $\alpha=0,0.25,0.5,0.75,1$ the original grey table is transformed to a table containing exact numbers. The data are presented in Tables 1, 2, 3, 4, 5 and 6 (In the source example, the values of the third column are grey).

\begin{tabular}{|c|c|c|c|c|}
\hline \multirow{2}{*}{ Suppliers } & \multicolumn{2}{|c|}{ Inputs } & \multicolumn{2}{c|}{ Outputs } \\
\cline { 2 - 5 } & $\mathbf{X}_{\mathbf{1}}$ & $\mathbf{X}_{\mathbf{2}}$ & $\mathbf{Y}_{\mathbf{1}}$ & $\mathbf{Y}_{\mathbf{2}}$ \\
\hline 1 & 253 & 5 & 50 & 1 \\
\hline 2 & 268 & 10 & 60 & 5.3 \\
\hline 3 & 259 & 3 & 40 & 4.6 \\
\hline 4 & 180 & 6 & 100 & 30 \\
\hline 5 & 257 & 4 & 45 & 30 \\
\hline 6 & 248 & 2 & 85 & 30 \\
\hline 7 & 272 & 8 & 70 & 30 \\
\hline 8 & 330 & 11 & 100 & 13.8 \\
\hline 9 & 327 & 9 & 90 & 4 \\
\hline 10 & 330 & 7 & 50 & 30 \\
\hline 11 & 321 & 16 & 250 & 26.4 \\
\hline 12 & 329 & 14 & 100 & 25.8 \\
\hline 13 & 281 & 15 & 80 & 25.8 \\
\hline 14 & 309 & 13 & 200 & 21.9 \\
\hline 15 & 291 & 12 & 40 & 9 \\
\hline 16 & 334 & 17 & 75 & 7 \\
\hline 17 & 249 & 1 & 90 & 6.3 \\
\hline 18 & 216 & 18 & 90 & 28.8 \\
\hline
\end{tabular}

Table 1 . Original values for $\alpha=0$ 


\begin{tabular}{|c|c|c|c|c|}
\hline \multirow[b]{2}{*}{ Suppliers } & \multicolumn{2}{|c|}{ Inputs } & \multicolumn{2}{|c|}{ Outputs } \\
\hline & $\mathrm{X}_{1}$ & $\mathbf{X}_{2}$ & $\mathbf{Y}_{1}$ & $Y_{2}$ \\
\hline 1 & 253 & 5 & 53.75 & 1 \\
\hline 2 & 268 & 10 & 62.5 & 5.3 \\
\hline 3 & 259 & 3 & 42.5 & 4.6 \\
\hline 4 & 180 & 6 & 115 & 30 \\
\hline 5 & 257 & 4 & 47.5 & 30 \\
\hline 6 & 248 & 2 & 92.5 & 30 \\
\hline 7 & 272 & 8 & 76.25 & 30 \\
\hline 8 & 330 & 11 & 120 & 13.8 \\
\hline 9 & 327 & 9 & 97.5 & 4 \\
\hline 10 & 330 & 7 & 57.5 & 30 \\
\hline 11 & 321 & 16 & 262.5 & 26.4 \\
\hline 12 & 329 & 14 & 112.5 & 25.8 \\
\hline 13 & 281 & 15 & 90 & 25.8 \\
\hline 14 & 309 & 13 & 237.5 & 21.9 \\
\hline 15 & 291 & 12 & 43.75 & 9 \\
\hline 16 & 334 & 17 & 77.5 & 7 \\
\hline 17 & 249 & 1 & 112.5 & 6.3 \\
\hline 18 & 216 & 18 & 105 & 28.8 \\
\hline
\end{tabular}

Table 2. Original values for $\alpha=0.25$

\begin{tabular}{|c|c|c|c|c|}
\hline \multirow{2}{*}{ Suppliers } & \multicolumn{2}{|c|}{ Inputs } & \multicolumn{2}{c|}{ Outputs } \\
\cline { 2 - 5 } & $\mathbf{X}_{\mathbf{1}}$ & $\mathbf{X}_{\mathbf{2}}$ & $\mathbf{Y}_{\mathbf{1}}$ & $\mathbf{Y}_{\mathbf{2}}$ \\
\hline 1 & 253 & 5 & 57.5 & 1 \\
\hline 2 & 268 & 10 & 65 & 5.3 \\
\hline 3 & 259 & 3 & 45 & 4.6 \\
\hline 4 & 180 & 6 & 130 & 30 \\
\hline 5 & 257 & 4 & 50 & 30 \\
\hline 6 & 248 & 2 & 100 & 30 \\
\hline 7 & 272 & 8 & 82.5 & 30 \\
\hline 8 & 330 & 11 & 140 & 13.8 \\
\hline 9 & 327 & 9 & 105 & 4 \\
\hline 10 & 330 & 7 & 65 & 30 \\
\hline 11 & 321 & 16 & 275 & 26.4 \\
\hline 12 & 329 & 14 & 125 & 25.8 \\
\hline 13 & 281 & 15 & 100 & 25.8 \\
\hline 14 & 309 & 13 & 275 & 21.9 \\
\hline 15 & 291 & 12 & 47.5 & 9 \\
\hline 16 & 334 & 17 & 80 & 7 \\
\hline 17 & 249 & 1 & 135 & 6.3 \\
\hline 18 & 216 & 18 & 120 & 28.8 \\
\hline & & & & \\
\hline
\end{tabular}

Table 3. Original values for $\alpha=0.5$ 


\begin{tabular}{|c|c|c|c|c|}
\hline \multirow[b]{2}{*}{ Suppliers } & \multicolumn{2}{|c|}{ Inputs } & \multicolumn{2}{|c|}{ Outputs } \\
\hline & $\mathrm{X}_{1}$ & $X_{2}$ & $\mathbf{Y}_{1}$ & $\mathbf{Y}_{2}$ \\
\hline 1 & 253 & 5 & 61.25 & 1 \\
\hline 2 & 268 & 10 & 67.5 & 5.3 \\
\hline 3 & 259 & 3 & 47.5 & 4.6 \\
\hline 4 & 180 & 6 & 145 & 30 \\
\hline 5 & 257 & 4 & 52.5 & 30 \\
\hline 6 & 248 & 2 & 107.5 & 30 \\
\hline 7 & 272 & 8 & 88.75 & 30 \\
\hline 8 & 330 & 11 & 160 & 13.8 \\
\hline 9 & 327 & 9 & 112.5 & 4 \\
\hline 10 & 330 & 7 & 72.5 & 30 \\
\hline 11 & 321 & 16 & 287.5 & 26.4 \\
\hline 12 & 329 & 14 & 137.5 & 25.8 \\
\hline 13 & 281 & 15 & 110 & 25.8 \\
\hline 14 & 309 & 13 & 312.5 & 21.9 \\
\hline 15 & 291 & 12 & 51.25 & 9 \\
\hline 16 & 334 & 17 & 82.5 & 7 \\
\hline 17 & 249 & 1 & 157.5 & 6.3 \\
\hline 18 & 216 & 18 & 135 & 28.8 \\
\hline
\end{tabular}

Table 4. Original values for $\alpha=0.75$

\begin{tabular}{|c|c|c|c|c|}
\hline \multirow{2}{*}{ Suppliers } & \multicolumn{2}{|c|}{ Inputs } & \multicolumn{2}{c|}{ Outputs } \\
\cline { 2 - 5 } & $\mathbf{X}_{\mathbf{1}}$ & $\mathbf{X}_{\mathbf{2}}$ & $\mathbf{Y}_{\mathbf{1}}$ & $\mathbf{Y}_{\mathbf{2}}$ \\
\hline 1 & 253 & 5 & 65 & 1 \\
\hline 2 & 268 & 10 & 70 & 5.3 \\
\hline 3 & 259 & 3 & 50 & 4.6 \\
\hline 4 & 180 & 6 & 160 & 30 \\
\hline 5 & 257 & 4 & 55 & 30 \\
\hline 6 & 248 & 2 & 115 & 30 \\
\hline 7 & 272 & 8 & 95 & 30 \\
\hline 8 & 330 & 11 & 180 & 13.8 \\
\hline 9 & 327 & 9 & 120 & 4 \\
\hline 10 & 330 & 7 & 80 & 30 \\
\hline 11 & 321 & 16 & 300 & 26.4 \\
\hline 12 & 329 & 14 & 150 & 25.8 \\
\hline 13 & 281 & 15 & 120 & 25.8 \\
\hline 14 & 309 & 13 & 350 & 21.9 \\
\hline 15 & 291 & 12 & 55 & 9 \\
\hline 16 & 334 & 17 & 85 & 7 \\
\hline 17 & 249 & 1 & 180 & 6.3 \\
\hline 18 & 216 & 18 & 150 & 28.8 \\
\hline & & & & \\
\hline
\end{tabular}

Table 5. Original values for $\alpha=1$ 
After measuring the efficiency for different levels $\alpha=0,0.25,0.5,0.75,1$ by DEA approach, the initial matrix of GRA method is the following:

\begin{tabular}{|c|c|c|c|c|c|}
\hline \multirow{2}{*}{ Suppliers } & $\boldsymbol{\alpha}=\mathbf{0}$ & $\boldsymbol{\alpha}=\mathbf{0 . 2 5}$ & $\boldsymbol{\alpha}=\mathbf{0 . 5}$ & $\alpha=\mathbf{0 . 7 5}$ & $\boldsymbol{\alpha} \mathbf{1}$ \\
\cline { 2 - 6 } & Efficiency & Efficiency & Efficiency & Efficiency & Efficiency \\
\hline 1 & 0.391 & 0.364 & 0.331 & 0.307 & 0.288 \\
\hline 2 & 0.337 & 0.32 & 0.288 & 0.264 & 0.246 \\
\hline 3 & 0.366 & 0.326 & 0.295 & 0.274 & 0.26 \\
\hline 4 & 1 & 1 & 1 & 1 & 1 \\
\hline 5 & 0.868 & 0.868 & 0.868 & 0.868 & 0.868 \\
\hline 6 & 1 & 1 & 1 & 1 & 1 \\
\hline 7 & 0.691 & 0.691 & 0.691 & 0.691 & 0.691 \\
\hline 8 & 0.493 & 0.53 & 0.533 & 0.536 & 0.538 \\
\hline 9 & 0.478 & 0.46 & 0.424 & 0.397 & 0.376 \\
\hline 10 & 0.628 & 0.628 & 0.628 & 0.628 & 0.628 \\
\hline 11 & 1 & 1 & 0.978 & 0.922 & 0.871 \\
\hline 12 & 0.513 & 0.512 & 0.51 & 0.504 & 0.499 \\
\hline 13 & 0.551 & 0.551 & 0.551 & 0.551 & 0.551 \\
\hline 14 & 0.918 & 1 & 1 & 1 & 1 \\
\hline 15 & 0.22 & 0.218 & 0.214 & 0.208 & 0.204 \\
\hline 16 & 0.288 & 0.284 & 0.272 & 0.251 & 0.234 \\
\hline 17 & 1 & 1 & 1 & 1 & 1 \\
\hline 18 & 0.8 & 0.8 & 0.8 & 0.8 & 0.8 \\
\hline
\end{tabular}

Table 6. Original matrix for different levels of $\alpha$

In Table 6, the steps corresponding to the GRA method are discussed below.

\subsection{Grey relation generation}

To generate grey relation, the original matrix is normalized by equation (10). The normalized matrix is given in Table 7. 


\begin{tabular}{|c|c|c|c|c|c|}
\hline \multirow{2}{*}{ Suppliers } & $\alpha=\mathbf{0}$ & $\alpha=\mathbf{0 . 2 5}$ & $\alpha=\mathbf{0 . 5}$ & $\alpha=\mathbf{0 . 7 5}$ & $\alpha=\mathbf{1}$ \\
\cline { 2 - 6 } & Efficiency & Efficiency & Efficiency & Efficiency & Efficiency \\
\hline $\mathrm{X}_{0}$ & 1.000 & 1.000 & 1.000 & 1.000 & 1.000 \\
\hline 1 & 0.219 & 0.187 & 0.149 & 0.125 & 0.106 \\
\hline 2 & 0.150 & 0.130 & 0.094 & 0.071 & 0.053 \\
\hline 3 & 0.187 & 0.138 & 0.103 & 0.083 & 0.070 \\
\hline 4 & 1.000 & 1.000 & 1.000 & 1.000 & 1.000 \\
\hline 5 & 0.831 & 0.831 & 0.832 & 0.833 & 0.834 \\
\hline 6 & 1.000 & 1.000 & 1.000 & 1.000 & 1.000 \\
\hline 7 & 0.604 & 0.605 & 0.607 & 0.610 & 0.612 \\
\hline 8 & 0.350 & 0.399 & 0.406 & 0.414 & 0.420 \\
\hline 9 & 0.331 & 0.309 & 0.267 & 0.239 & 0.216 \\
\hline 10 & 0.523 & 0.524 & 0.527 & 0.530 & 0.533 \\
\hline 11 & 1.000 & 1.000 & 0.972 & 0.902 & 0.838 \\
\hline 12 & 0.376 & 0.376 & 0.377 & 0.374 & 0.371 \\
\hline 13 & 0.424 & 0.426 & 0.429 & 0.433 & 0.436 \\
\hline 14 & 0.895 & 1.000 & 1.000 & 1.000 & 1.000 \\
\hline 15 & 0.000 & 0.000 & 0.000 & 0.000 & 0.000 \\
\hline 16 & 0.087 & 0.084 & 0.074 & 0.054 & 0.038 \\
\hline 17 & 1.000 & 1.000 & 1.000 & 1.000 & 1.000 \\
\hline 18 & 0.744 & 0.744 & 0.746 & 0.747 & 0.749 \\
\hline
\end{tabular}

Table 7. The normalized matrix

Where the reference sequence is defined as $X_{0}=(1,1,1,1,1)$.

\subsection{The calculation of the grey relational coefficient}

Using relation (13), the grey relational coefficients are calculated for all the values and the results are presented in Table 8.

\begin{tabular}{|c|c|c|c|c|c|}
\hline \multirow{2}{*}{ Suppliers } & $\boldsymbol{\alpha = 0}$ & $\boldsymbol{\alpha}=\mathbf{0 . 2 5}$ & $\boldsymbol{\alpha}=\mathbf{0 . 5}$ & $\boldsymbol{\alpha}=\mathbf{0 . 7 5}$ & $\boldsymbol{\alpha}=\mathbf{1}$ \\
\cline { 2 - 6 } & Efficiency & Efficiency & Efficiency & Efficiency & Efficiency \\
\hline 1 & 0.390 & 0.381 & 0.370 & 0.364 & 0.359 \\
\hline 2 & 0.370 & 0.365 & 0.356 & 0.350 & 0.345 \\
\hline 3 & 0.381 & 0.367 & 0.358 & 0.353 & 0.350 \\
\hline 4 & 1.000 & 1.000 & 1.000 & 1.000 & 1.000 \\
\hline 5 & 0.747 & 0.748 & 0.749 & 0.750 & 0.751 \\
\hline 6 & 1.000 & 1.000 & 1.000 & 1.000 & 1.000 \\
\hline 7 & 0.558 & 0.559 & 0.560 & 0.562 & 0.563 \\
\hline 8 & 0.435 & 0.454 & 0.457 & 0.460 & 0.463 \\
\hline 9 & 0.428 & 0.420 & 0.406 & 0.396 & 0.389 \\
\hline 10 & 0.512 & 0.512 & 0.514 & 0.516 & 0.517 \\
\hline 11 & 1.000 & 1.000 & 0.947 & 0.835 & 0.755 \\
\hline 12 & 0.445 & 0.445 & 0.445 & 0.444 & 0.443 \\
\hline 13 & 0.465 & 0.465 & 0.467 & 0.469 & 0.470 \\
\hline 14 & 0.826 & 1.000 & 1.000 & 1.000 & 1.000 \\
\hline 15 & 0.333 & 0.333 & 0.333 & 0.333 & 0.333 \\
\hline 16 & 0.354 & 0.353 & 0.351 & 0.346 & 0.342 \\
\hline 17 & 1.000 & 1.000 & 1.000 & 1.000 & 1.000 \\
\hline 18 & 0.661 & 0.662 & 0.663 & 0.664 & 0.666 \\
\hline
\end{tabular}

Table 8. The grey relational coefficients 


\subsection{The calculation of the grey relational degree}

The information in Table 6 is used to calculate the grey relational coefficients $\gamma\left(x_{0 j}, x_{i j}\right)$, grey relational degree, ranking of suppliers based on GRA, ranking based on TOPSIS (Technique for Order-Preference by Similarity to Ideal Solution) and SAW (Sample Additive Weighting), and the results are presented in Table 9.

\begin{tabular}{|c|c|c|c|c|}
\hline & & \multicolumn{3}{|c|}{ Ranking } \\
\hline Suppliers & Grey relational degree & GRA & TOPSIS & SAW \\
\hline 1 & 0.373 & 14 & 14 & 14 \\
\hline 2 & 0.357 & 16 & 16 & 16 \\
\hline 3 & 0.362 & 15 & 15 & 15 \\
\hline 4 & 1.000 & 1 & 1 & 1 \\
\hline 5 & 0.749 & 6 & 6 & 6 \\
\hline 6 & 1.000 & 1 & 2 & 1 \\
\hline 7 & 0.560 & 8 & 8 & 8 \\
\hline 8 & 0.454 & 11 & 11 & 11 \\
\hline 9 & 0.408 & 13 & 13 & 13 \\
\hline 10 & 0.514 & 9 & 9 & 9 \\
\hline 11 & 0.908 & 5 & 5 & 5 \\
\hline 12 & 0.444 & 12 & 12 & 12 \\
\hline 13 & 0.467 & 10 & 10 & 10 \\
\hline 14 & 0.965 & 4 & 4 & 4 \\
\hline 15 & 0.333 & 18 & 18 & 18 \\
\hline 16 & 0.349 & 17 & 17 & 17 \\
\hline 17 & 1.000 & 1 & 3 & 1 \\
\hline 18 & 0.663 & 7 & 7 & 7 \\
\hline
\end{tabular}

Table 9. The grey relational degree and ranking of suppliers

Based on Table 9, suppliers 17, 6 and 4 are selected as the efficient suppliers. To demonstrate the quality of the obtained solution, efficiency of each supplier and their ranking by the average method, MRA method, and the proposed approach are compared in Table 10: 


\begin{tabular}{|c|c|c|c|c|}
\hline Suppliers & $A_{j}=\left[\underline{\left.\theta_{j}, \overline{\theta_{j}}\right]}\right.$ & Proposed & Average & MRA \\
\hline 1 & {$[0.221,0.509]$} & 14 & 14 & 14 \\
\hline 2 & {$[0.215,0.393]$} & 16 & 16 & 16 \\
\hline 3 & {$[0.221,0.425]$} & 15 & 15 & 15 \\
\hline 4 & {$[1.332,1.607]$} & 3 & 3 & 3 \\
\hline 5 & {$[0.868,0.868]$} & 4 & 7 & 7 \\
\hline 6 & {$[2.014,2.07]$} & 2 & 2 & 2 \\
\hline 7 & {$[0.691,0.691]$} & 8 & 8 & 8 \\
\hline 8 & {$[0.322,0.868]$} & 12 & 11 & 9 \\
\hline 9 & {$[0.282,0.638]$} & 13 & 13 & 13 \\
\hline 10 & {$[0.628,0.628]$} & 9 & 9 & 10 \\
\hline 11 & {$[0.753,1.444]$} & 6 & 5 & 5 \\
\hline 12 & {$[0.471,0.669]$} & 11 & 12 & 12 \\
\hline 13 & {$[0.551,0.672]$} & 10 & 10 & 11 \\
\hline 14 & {$[0.709,1.6]$} & 7 & 4 & 4 \\
\hline 15 & {$[0.186,0.28]$} & 18 & 18 & 18 \\
\hline 16 & {$[0.212,0.327]$} & 17 & 17 & 17 \\
\hline 17 & {$[1.565,4.235]$} & 1 & 1 & 1 \\
\hline 18 & {$[0.8,1.051]$} & 5 & 6 & 6 \\
\hline
\end{tabular}

Table 10. The efficiency of suppliers and the ranking results

\subsection{Comparing the results of the model}

This section deals with ranking of suppliers. Table 11 presents the suppliers ranking done by all the aforementioned methods:

\begin{tabular}{|c|c|c|c|c|c|c|}
\hline \multirow{2}{*}{ Suppliers } & \multicolumn{5}{|c|}{ Ranking } & \multicolumn{3}{c|}{ Ranking } \\
\cline { 2 - 7 } & GRA & SAW & TOPSIS & MRA & Average & Proposed \\
\hline 1 & 14 & 14 & 14 & 14 & 14 & 14 \\
\hline 2 & 16 & 16 & 16 & 16 & 16 & 16 \\
\hline 3 & 15 & 15 & 15 & 15 & 15 & 15 \\
\hline 4 & 1 & 1 & 1 & 3 & 3 & 3 \\
\hline 5 & 6 & 6 & 6 & 4 & 7 & 7 \\
\hline 6 & 1 & 1 & 2 & 2 & 2 & 2 \\
\hline 7 & 8 & 8 & 8 & 8 & 8 & 8 \\
\hline 8 & 11 & 11 & 11 & 12 & 11 & 9 \\
\hline 9 & 13 & 13 & 13 & 13 & 13 & 13 \\
\hline 10 & 9 & 9 & 9 & 9 & 9 & 10 \\
\hline 11 & 5 & 5 & 5 & 6 & 5 & 5 \\
\hline 12 & 12 & 12 & 12 & 11 & 12 & 12 \\
\hline 13 & 10 & 10 & 10 & 10 & 10 & 11 \\
\hline 14 & 4 & 4 & 4 & 7 & 4 & 4 \\
\hline 15 & 18 & 18 & 18 & 18 & 18 & 18 \\
\hline 16 & 17 & 17 & 17 & 17 & 17 & 17 \\
\hline 17 & 1 & 1 & 3 & 1 & 1 & 1 \\
\hline 18 & 7 & 7 & 7 & 5 & 6 & 6 \\
\hline & & & & & & \\
\hline
\end{tabular}

Table 11. Comparing the obtained rankings 
According to Table 11, it is clear that GRA, TOPSIS, and SAW approaches have yielded the same results. In addition, by comparing the ranking obtained by GRA method with those of MRA, average, and the proposed approach, we notice that suppliers 17, 6, and 4 are selected as the efficient ones. It is worth reminding that the proposed approach works based on interval efficiency by solving the models introduced in (28) and (29). A Comparison demonstrates that the proposed approach provides satisfactory and acceptable results. Additionally, the amount of required computation associated with the proposed approach is less than that of model (27). Therefore, the proposed model in addition to providing acceptable results avoids timeconsuming computation and consequently reduces the solving time. To name other advantage of the proposed model, we can point out that it is capable of making decision involving different levels of risk.

\section{Conclusion and directions for future work}

The critical role of suppliers in success of an organization makes the topic of evaluation and selection of suppliers a crucial task. Data envelopment analysis (DEA) has been widely applied in evaluating and selecting suppliers which considers the necessary inputs and outputs and then analyzes the efficiency of decision making units. Managers to make a decision can take two approaches: one is decision making in a static environment and the other is decision making in a stochastic environment. But the second one is closer to reality. In this regard, grey number theory is a tool to be used for coping with uncertainty. Hence, to make a decision in a stochastic environment, by applying a hybrid of data envelopment analysis and grey number theory, we can come to a right decisions. In this paper, a model for evaluating and selecting efficient suppliers under a stochastic environment is proposed in which a hybrid of data envelopment analysis and grey relational analysis is utilized. The proposed approach in addition to providing acceptable results avoids time-consuming computations and consequently reduces the solution time. To name another advantage of the proposed model, we can point out its capability of making decision involving different levels of risk. Finally, we present a novel ranking method for grey numbers.

Application of AHP, ANP or QFD for finding weights of evaluating criteria in grey relational analysis and using a hybrid of rough and grey numbers in the model are suggestions for future studies. 


\section{References}

Basnet, C., \& Leung, J.M. Y. (2005). Inventory lot-sizing with supplier selection. Computers \& Operations Research, 32(1), 1-14. http://dx.doi.org/10.1016/S0305-0548(03)00199-0

Charnes, A., Cooper, W.W., \& Rhodes, E. L. (1978). Measuring the efficiency of decision making units. European Journal of Operational Research, 2(6), 429-44. http://dx.doi.org/10.1016/03772217(78)90138-8

Chen, W.H. (2005). Distribution system restoration using the hybrid fuzzy-grey method. IEEE Transactions on Power Systems, 20, 199-205. http://dx.doi.org/10.1109/TPWRS.2004.841234

Chen, Y., \& Huang, P. (2007). Bi-negotiation integrated AHP in suppliers selection. International Journal of Operations \& Production Management, 27, 1254-1274. http://dx.doi.org/10.1108/01443570710830629

Choy, K.L., \& Lee, W.B. (2002). A generic tool for the selection and management of supplier relationships in an outsourced manufacturing environment: The application of case based reasoning. Logistics Information Management, 15, 235-253.

http://dx.doi.org/10.1108/09576050210436093

Cooper, W., Seiford, L.M., \& Tone, K. (2000). Data Envelopment Analysis: A comprehensive text with models, applications, references and DEA-solver software. Kluwer Academic publisher, Boston.

Demirtas, E.A., \& Üstün, Ö. (2008). An integrated multiobjective decision making process for supplier selection and order allocation. Omega, 36, 76-90.

http://dx.doi.org/10.1016/j.omega.2005.11.003

Deng, J. (1982). Control problems of grey systems. Systems and Control Letters, 1, 288-294. http://dx.doi.org/10.1016/S0167-6911(82)80025-X

Farzipoor Saen, R. (2010). Developing a new data envelopment analysis methodology for supplier selection in the presence of both undesirable outputs and imprecise data. International Journal of Advanced Manufacturing Technology, 51, 1243-1250. http://dx.doi.org/10.1007/s00170-010-2694-3

Garfamy, R. (2006). A data envelopment analysis approach based on total cost of ownership for supplier selection. Journal of Enterprise Information Management, 19, 662-678. http://dx.doi.org/10.1108/17410390610708526

Gencer, C., \& Gürpinar, D. (2007). Analytic network process in supplier selection: A case study in an electronic firm. Applied mathematical modeling, 31, 2475-2486.

http://dx.doi.org/10.1016/j.apm.2006.10.002 
Ghodsypour, S.H., \& O'Brien, C. (1998). A decision support system for supplier selection using an integrated analytic hierarchy process and linear programming. International Journal of Production Economics, 1, 56-57.

Hong, G., Park, S., Jang, D., \& Rho, H. (2005). An effective supplier selection method for constructing a competitive supply-relationship. Expert Systems with Applications, 28, 629639. http://dx.doi.org/10.1016/j.eswa.2004.12.020

Hou, J., \& Su, D. (2007). EJB-MVC oriented supplier selection system for mass customization. Journal of Manufacturing Technology Management, 18, 54-71. http://dx.doi.org/10.1108/17410380710717643

Kahraman, C., Cebeci, U., \& Ulukan, Z. (2003). Multi-criteria supplier selection using fuzzy AHP. Logistics Information Management, 16, 382-394. http://dx.doi.org/10.1108/09576050310503367

Lau, H., Lee, C., Ho. G., \& Pun, K. (2006). A performance benchmarking system to support supplier selection. International Journal of Business Performance Management, 8, 132-151. http://dx.doi.org/10.1504/IJBPM.2006.009033

Lin, C.T., Chang, C.W., \& Chen, C.B. (2006). The worst ill-conditioned silicon wafer machine detected by using grey relational analysis. International Journal of Advanced Manufacturing Technology, 31, 388-395. http://dx.doi.org/10.1007/s00170-006-0685-1

Mendoza, A., Santiago, E., \& Ravindran, A.R. (2008). A three-phase multicriteria method to the supplier selection problem. International Journalof Industrial Engineering, 15, 195-210.

Morán, J., Granada, E., Míguez, J.L., \& Porteiro, J. (2006). Use of grey relational analysis to assess and optimize small biomass boilers. Fuel Processing Technology, 87, 123-127. http://dx.doi.org/10.1016/j.fuproc.2005.08.008

Muralidharan, C., Anantharaman, N., \& Deshmukh, S. (2002). A multi-criteria group decision making model for supplier rating. Journal of supply chain management, 38, 22-33. http://dx.doi.org/10.1111/j.1745-493X.2002.tb00140.x

Narasimhan, R., Talluri, S., \& Mendez, D. (2001). Supplier evaluation and rationalization via data envelopment analysis: an empirical examination. Journal of supply chain management, 37, 28-37. http://dx.doi.org/10.1111/j.1745-493X.2001.tb00103.x

Narasimhan, R., Talluri, S., \& Mahapatra, S. (2006). Multiproduct, multicriteria model for supplier selection with product life-cycle considerations. Decision Sciences, 37, 577-603. http://dx.doi.org/10.1111/j.1540-5414.2006.00139.x

Olson, D.L., \& Wu, D. (2006). Simulation of fuzzy multiattribute models for grey relationships. European Journal of Operational Research, 175, 111-120. 
Saen, R. (2007). A new mathematical approach for suppliers selection: accounting for nonhomogeneity is important. Applied mathematics and computation, 185, 84-95. http://dx.doi.org/10.1016/j.amc.2006.07.071

Sarkar, A., \& Mohapatra, P. (2006). Evaluation of supplier capability and performance: A method for supply base reduction. Journal of Purchasing and Supply Management, 12, 148-163. http://dx.doi.org/10.1016/j.pursup.2006.08.003

Talluri, S., \& Baker, R. (2002). A multi-phase mathematical programming approach for effective supply chain design. European Journal of Operational Research, 141, 544-558. http://dx.doi.org/10.1016/S0377-2217(01)00277-6

Talluri, S., \& Narasimhan, R. (2005). A Note on a Methodology for Supply Base Optimization. IEEE Transactions on Engineering Management, 52, 130-139.

http://dx.doi.org/10.1109/TEM.2004.839960

Talluri, S., Narasimhan, R., \& Nair, A. (2006). Vendor performance with supply risk: a chanceconstrained DEA approach. International Journal of Production Economics, 100, 212-222. http://dx.doi.org/10.1016/j.ijpe.2004.11.012

Wu, H.H. (2002). A comparative study of using grey relational analysis in multiple attribute decision making problems. Quality Engineering, 15, 209-217. http://dx.doi.org/10.1081/QEN120015853

Wu, T., Shunk, D., Blackhurst, J., \& Appalla, R. (2007). AIDEA: a methodology for supplier evaluation and selection in a supplier-based manufacturing environment. International Journal of Manufacturing Technology and Management, 11, 174-192.

http://dx.doi.org/10.1504/IJMTM.2007.013190

Wu, D., \& Olson, D.L. (2010). Fuzzy multiattribute grey related analysis using DEA. Computers and Mathematics with Applications, 60, 166-174. http://dx.doi.org/10.1016/j.camwa.2010.04.043

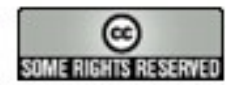

Article's contents are provided on a Attribution-Non Commercial 3. 0 Creative commons license. Readers are allowed to copy, distribute and communicate article's contents, provided the author's and Journal of Industrial Engineering and Management's names are included. It must not be used for commercial purposes. To see the complete license contents, please visit http://creativecommons. org/licenses/by-nc/3. 0/. 